\title{
Patrimônio geomorfológico e interpretação ambiental em trilhas de montanha (Parque Nacional da Serra dos Órgãos, Rio de Janeiro, Brasil)
}

\author{
Geomorphological heritage and environmental interpretation in \\ mountain trails (Serra dos Órgãos National Park, Rio de \\ Janeiro, Brazil)
}

Fernando Amaro Pessoa, CEFET/RJ - campus Petrópolis, Brasil, fernando.pessoa@cefet-rj.br (D) https://orcid.org/0000-0003-4562-4274

Adriel Filipe Soares Brito, Departamento de Geologia, Universidade Federal do Rio de Janeiro, Brasil, adrielfilipe01@gmail.com

(1) https://orcid.org/0000-0002-1948-4362

Fabio Feler Pacheco, Departamento de Geologia, Universidade Federal do Rio de Janeiro, Brasil, feler.fabio@gmail.com

(D) https://orcid.org/0000-0002-9152-2220

Maria Naíse de Oliveira Peixoto, Departamento de Geografia, Universidade Federal do Rio de Janeiro, Brasil, naise@ufrj.br

(1) https://orcid.org/0000-0002-5518-1588

Kátia Leite Mansur, Departamento de Geologia, Universidade Federal do Rio de Janeiro, Brasil, katia@geologia.ufrj.br

(1) https://orcid.org/0000-0003-4151-7463

Resumo: Promover a valorização da geodiversidade e de seu patrimônio geomorfológico em unidades de conservação, a partir de uma perspectiva interdisciplinar, é de suma importância e contribui para o uso sustentável destes territórios e seu entorno. O Parque Nacional da Serra dos Órgãos (PARNASO), localizado na Serra do Mar, região Sudeste do Brasil, possui um conjunto de montanhas com grande valor estético que possibilita ressaltar outros valores e usos, como o científico, o didático e o turístico dos seus geomorfossítios, por meio de uma interpretação ambiental em trilhas, contribuindo no cumprimento de seus objetivos de acordo com o Sistema Nacional de Unidades de Conservação. O presente trabalho apresenta uma proposta de caracterização da geodiversidade do PARNASO e a implementação de estratégias de gestão e divulgação do patrimônio geomorfológico em trilhas de montanha, a partir da elaboração de roteiros geoturísticos e didáticos, com o auxílio do aplicativo de navegação $W_{i k i l o c}{ }^{\circledR}$. Neste sentido, detalhar, registrar e divulgar aspectos da geodiversidade em trilhas contribui no destaque da dimensão estética da paisagem, da sua dimensão dinâmica, ao identificar e visualizar processos e mudanças, e também da sua imbricação de escalas, seja espacial ou temporal. Então, é necessário ressaltar uma abordagem mais integrada ligando a geodiversidade, a biodiversidade, a paisagem e as pessoas, aspecto central em que a presente pesquisa pretende contribuir.

Palavras-chave: Patrimônio Geomorfológico; Geomorfossítios; Trilhas; PARNASO.

Abstract: Promoting the appreciation of geodiversity and its geomorphological heritage in protected areas, from an interdisciplinary perspective, is of paramount importance and contributes to the sustainable use of these territories and their surroundings. Serra dos Órgãos National Park (PARNASO), located in Serra do Mar, Southeastern Brazil, has a set of mountains with great aesthetic value that makes it possible to highlight other values and uses, such as the scientific, didactic and tourism of its geomorphosites through an environmental interpretation in trails, contributing to the fulfilment of its objectives according to the National System of Conservation Units. The present work 
presents a proposal for the characterization of PARNASO geodiversity, and the implementation of management strategies and dissemination of geomorphological heritage in mountain trails, based on the elaboration of geotouristic and didactic itineraries with the aid of the Wikiloc ${ }^{\circledR}$ navigation application. In this sense, detailing, recording and disseminating aspects of trail geodiversity contributes to highlighting the aesthetic dimension of the landscape, its dynamic dimension, identifying and visualizing processes and changes, and also its imbrication of scales, whether spatial or temporal. Therefore, it is necessary to emphasize a more integrated approach linking geodiversity, biodiversity, landscape and people, a central aspect in which this research intends to contribute.

Keywords: Geomorphological Heritage; Geomorphosites; Trails; PARNASO.

\section{Introdução}

No Brasil, as áreas protegidas ainda são tímidas na adoção das diretrizes propostas pela União Internacional para a Conservação da Natureza (IUCN) para gestão da geodiversidade, por isso, atualmente, os elementos da biodiversidade e da geodiversidade não são tratados de forma igualitária e integrada, resultando em políticas públicas de conservação, divulgação e utilização do patrimônio natural que tendem a permanecer na abordagem tradicional da conservação da natureza. Essa abordagem omite o suporte da geodiversidade para o desenvolvimento da biodiversidade, pois somente com as condições abióticas essenciais é que os diferentes organismos bióticos encontram condições para sua subsistência.

Assim, promover a valorização da geodiversidade e de seu patrimônio geológico/geomorfológico em unidades de conservação, com destaque para os parques nacionais, a partir de uma perspectiva interdisciplinar, é de suma importância, pois contribui para o uso sustentável e conservação destes territórios e seu entorno. Além disso, contribui com ações de disseminação das geociências acerca das áreas protegidas, através de mecanismos que busquem incentivar e facilitar a experiência dos visitantes, a partir do aproveitamento pedagógico e turístico dos seus pontos de interesse da geodiversidade.

O Parque Nacional da Serra dos Órgãos (PARNASO) destaca-se entre os que possuem o maior número de pesquisas desenvolvidas ou em desenvolvimento e encontra-se entre os dez parques nacionais mais visitados do país, o que, em parte, está associado à sua proximidade geográfica e inserção territorial nos três estados mais populosos do país (Rio de Janeiro, São Paulo e Minas Gerais) e a importantes universidades e centros de pesquisas. Apesar de apresentarem como atrativo principal as fabulosas feições de relevo, representativas de toda a região Sudeste no contexto do Rift Continental do Sudeste do Brasil (Riccomini, 1989), verifica-se que pouca informação sobre a geodiversidade é transmitida aos visitantes. Diante do exposto, é possível afirmar que, nas inúmeras escalas possíveis, a geodiversidade dificilmente é menos notável que a biodiversidade, situação que se materializa no PARNASO.

Nesse sentido, o PARNASO vem se notabilizando pelo seu expressivo potencial de divulgação científica, representado em especial nas suas diversas trilhas - com destaque para a Travessia Petrópolis-Teresópolis - onde têm sido buscados meios 
de incentivo e melhoria da experiência dos visitantes, levando em consideração sua diversidade natural. A Travessia Petrópolis-Teresópolis é uma trilha que possui aproximadamente $25 \mathrm{~km}$ de extensão, com significativa variação de altitude e realizada, tradicionalmente, em três dias de caminhada.

O conjunto de montanhas que forma a Serra dos Órgãos possui um excepcional valor estético que possibilita ressaltar outros valores e usos, conforme aborda Brilha (2018). Um destes usos corresponde ao próprio uso geocientífico, que produz conhecimentos significativos sobre como a geosfera trabalha e interage com outros sistemas (biosfera, hidrosfera e atmosfera). A geoeducação se constitui em outro tipo de uso que pode ser realizado por professores ligados às geociências, apresentando questões referentes às pesquisas científicas realizadas sobre a geodiversidade local. Por fim, o uso econômico através do geoturismo e a prática de esportes, lazer e recreação, peculiares às características naturais das áreas consideradas, configurase como outra vertente de uso, que se relaciona com as comunidades locais.

É dentro deste contexto que tais propostas podem ser efetivadas em trilhas dessa unidade de conservação de proteção integral, contribuindo no cumprimento de seus objetivos de acordo com o Sistema Nacional de Unidades de Conservação, ao possibilitar a realização de pesquisas científicas e o desenvolvimento de atividades de educação e interpretação ambiental, de recreação em contato com a natureza e de turismo ecológico.

Com base nessa abordagem, a história natural do Rio de Janeiro e suas perspectivas físicas, ecológicas e socioambientais formam a base para uma compreensão maior de sua importância. Estes temas ficam explícitos na Travessia Petrópolis-Teresópolis, a trilha mais visitada do PARNASO e representativa de toda sua geodiversidade e serviços ecossistêmicos associados.

A partir da problemática apresentada, torna-se necessário realizar estratégias de valorização dos sítios de interesse geológico, geomorfológico e paisagístico, de modo a valorizar a geodiversidade presente na área. Além disso, a gestão sustentável da geodiversidade pode ser realizada através da divulgação dos serviços ecossistêmicos abióticos, o que pode contribuir para a gestão dos geossítios e sítios da geodiversidade mais representativos de sua história geológica, em que a interação com o ambiente natural pode contribuir na promoção de relações mais harmoniosas entre sociedade e natureza, tendo o conhecimento como fundamental em estratégias de preservação e/ou conservação.

Baseado nesses fatos, esta pesquisa teve como objetivo contribuir com o Instituto Chico Mendes de Conservação da Biodiversidade (ICMBio), órgão responsável pela gestão das unidades de conservação federais brasileiras, na divulgação e gestão do patrimônio geológico e geomorfológico, através do aumento do senso de pertencimento da sociedade em relação ao meio ambiente de forma integrada (bio, geo e também sociodiversidade). Para isso, foi realizada uma caracterização da geodiversidade e serviços ecossistêmicos associados da Travessia PetrópolisTeresópolis e posterior elaboração de um roteiro geoturístico e didático com o auxílio 
do aplicativo de navegação $W_{i k i l o c}{ }^{\circledR}$, além de inserir seus principais geossítios no Sistema de Cadastro e Quantificação de Geossítios e de Sítios da Geodiverdade (GEOSSIT) do Serviço Geológico do Brasil (CPRM).

\section{Patrimônio geomorfológico e interpretação ambiental: potencial turístico e didático em trilhas de montanha a partir de uma abordagem geossistêmica}

O patrimônio geomorfológico pode ser considerado como o conjunto de formas de relevo dignas de serem protegidas e transmitidas às gerações futuras, sendo uma parte do patrimônio geológico, um componente do patrimônio natural (Reynard, 2009) e que, ao se considerar suas especificidades, é possível ressaltar a grande contribuição da comunidade científica de geógrafos e geomorfólogos (Coratza, Hobléa, 2018).

Este conceito apresenta uma abordagem integradora, tendo em vista que os processos geomorfológicos e as formas de relevo têm um papel fundamental no suporte dos hábitats, espécies e na provisão de serviços ecossistêmicos/ambientais (Gray, 2013), além de contemplar também aspectos culturais que possuem valor patrimonial, pelo menos parcialmente, determinado pelo contexto geomorfológico em que estão inseridos.

O termo geomorfossítio, proposto por Panizza (2001), é o mais utilizado para se referir às formas de relevo que compõem o patrimônio geomorfológico, a partir dos valores que Ihes são atribuídos, numa perspectiva ampla do conceito, tais como: cênicos, científicos, socioeconômicos e culturais. Esses valores, numa abordagem holística, podem ser vistos como inter-relacionados e interdependentes, o que evidencia as relações entre sociedade e natureza. Também é importante considerar que a integração de fatores relacionados ao papel social atribuído por comunidades fora do campo das Ciências da Terra com aquelas geralmente reconhecidas pelos geocientistas, podem contribuir para a qualificação de objetos geomorfológicos como tendo valor patrimonial numa perspectiva sociocultural (Coratza, Hobléa, 2018).

Como exemplo, podemos citar o Dedo de Deus, montanha mais conhecida da Serra dos Órgãos (Figura 1), que possui destaque sistematizado desde as últimas décadas do século XIX, seja pela representação nas pranchas litografadas do naturalista alemão von Martius (Assis Júnior, 2011), ou pelo desafio que ela representava ao esporte montanhismo, tendo imagens suas divulgadas pela Europa como "a montanha impossível de ser subida" (Lucena, 2008). Assim, além do seu valor científico, possui valor histórico, cultural, estético e socioeconômico, evidenciado em diferentes perspectivas, como durante a Travessia Petrópolis-Teresópolis (Figura 2), por exemplo. Assim, valores paisagísticos e culturais devem ser enfatizados, destacando-se a importância do processo de percepção, a paisagem percebida e com grande influência da cultura (Reynard, Giusti, 2018). 


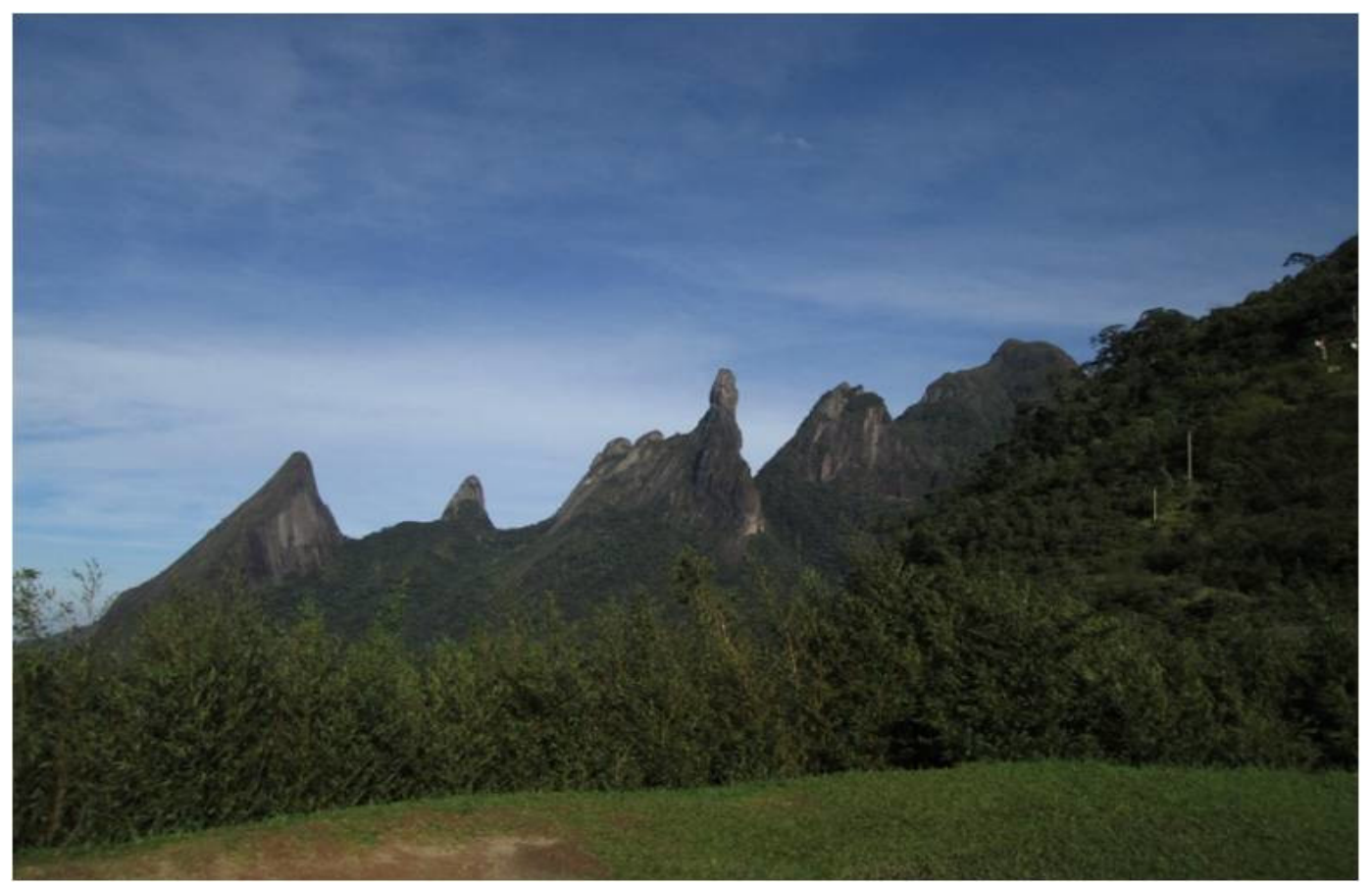

Figura 1: Complexo de montanhas do Dedo de Deus. Perspectiva a partir do mirante do Alto Soberbo (Teresópolis, RJ), local de fácil acesso na rodovia BR 116. Da esquerda para a direita: Escalavrado, Dedo de Nossa Senhora, Dedo de Deus, Cabeça de Peixe e Santo Antônio.

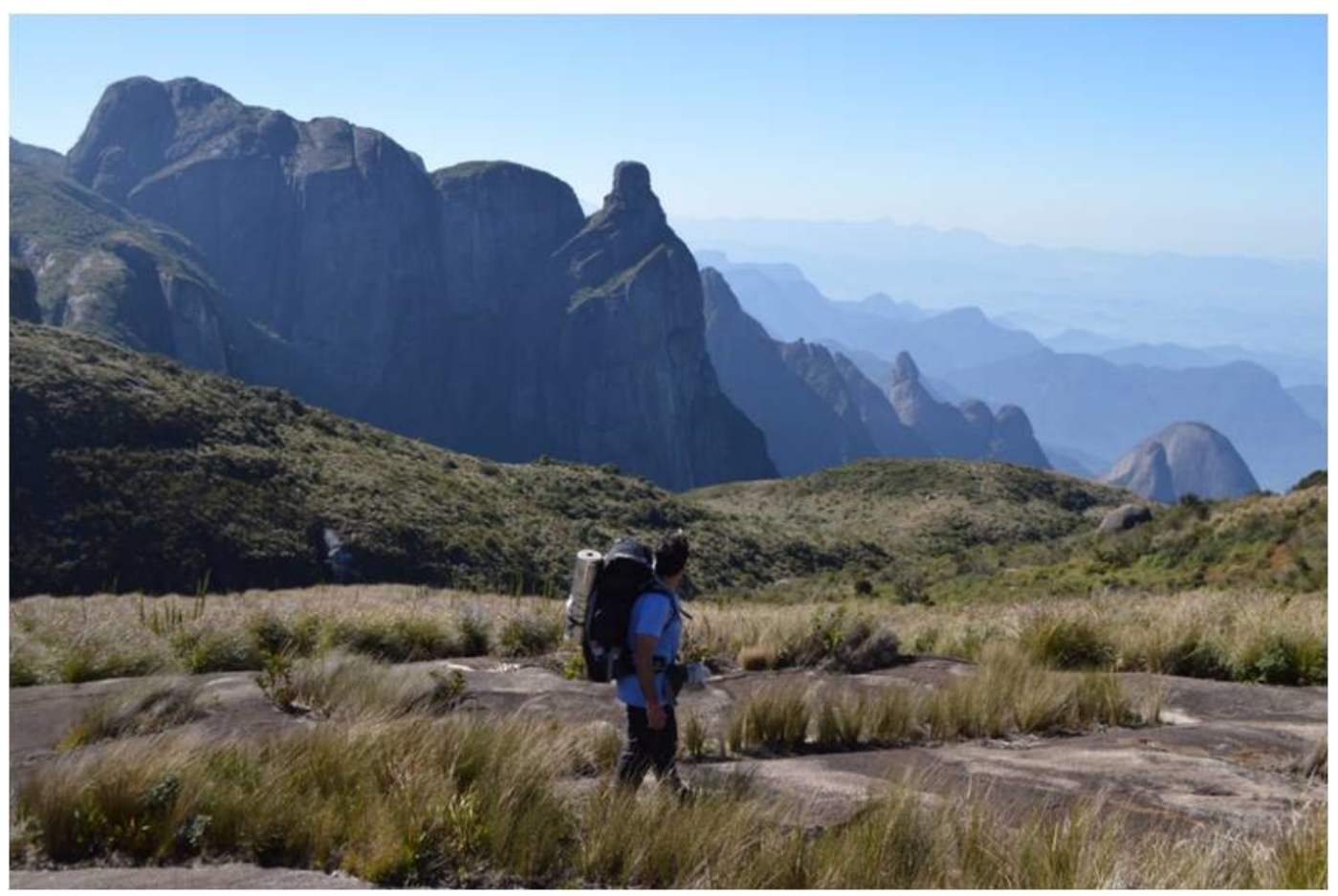

Figura 2: Perspectiva do Dedo de Deus da Travessia Petrópolis-Teresópolis. À esquerda, destaque para a Pedra do Sino (ponto culminante da Serra dos Órgãos) e a Pedra do Garrafão.

De acordo com Reynard (2009), os geomorfossítios possuem três características principais que os caracterizam como distintos tipos de patrimônio geológico: a dimensão estética, a dimensão dinâmica e a imbricação de escalas. São geralmente muito espetaculares e populares, como uma cachoeira, o pico de uma montanha, blocos erráticos que se constituem atraentes visualmente e que sempre despertam 
grande interesse e atraem atenção das pessoas. Tais características, evidentes em qualquer abordagem sobre a Serra dos Órgaõs, conforme ilustrado nas fotos apresentadas, podem facilitar o conhecimento e consciência das questões ambientais no público em geral, desempenhando importante papel na promoção de paisagens e no geoturismo.

Essa perspectiva de análise acaba por ressaltar aspectos ligados à abordagem geossistêmica na interpretação ambiental das paisagens, através da concepção da Teoria dos Geossistemas, considerado por Sochava (1978) como o espaço terrestre de todas as dimensões, onde todos os componentes naturais individuais encontramse em uma relação sistêmica uns com os outros e, como integridade, interatuam com a esfera cósmica e com a sociedade humana. Essa teoria possui como foco central o estudo da dinâmica do meio natural, em que a divisão dos geossistemas em componentes abióticos e bióticos torna-se inadequada, ao considerarmos que ambos os aspectos estão estreitamente relacionados. Este autor ressalta, por exemplo, não ser possível analisar nenhum sistema geográfico sem levar em consideração o ponto de partida energético e a água como condição necessária do processo físicogeográfico, sendo esses componentes mais importantes do que a biota, ou ao menos tendo o mesmo valor que a biota. Porém, é necessário considerar o geossistema não só como um sistema natural, já que inclui as transformações causadas por fatores sociais e econômicos (Rodriguez, Silva, 2019).

Nessa abordagem geossistêmica, propostas de interpretação ambiental a partir do geoturismo podem ajudar a melhorar a experiência do visitante através da apreciação do cenário, tornando-se consciente de maravilhas naturais, participando de atividades recreativas ao ar livre ou simplesmente desfrutando do ar livre (Newsome, Dowling, 2018). Tais atividades possibilitam conexões do patrimônio geomorfológico com componentes culturais, estéticos e históricos, permitindo uma apreciação mais holística da natureza, pessoas e paisagem para um público mais amplo. Essa perspectiva ressalta o uso público em áreas protegidas como aliado da conservação, percepção de extrema importância e relativamente nova no Brasil, porém já bastante utilizada em outros países (Menezes, 2017).

Tais questões, desenvolvidas através de roteiros geoturísticos e didáticos, necessitam de uma linguagem de comunicação que seja compreensível por não-especialistas, pois do contrário acaba por gerar um rápido desinteresse, o que representa um grande desafio a partir do pressuposto de que falar em linguagem simples e cotidiana não diminui a importância do assunto, e sim contribui sendo acessível a um número maior de pessoas. Assim, uma estratégia de interpretação precisa ser trabalhada, discutida e acordada pelo maior número das partes envolvidas, em que o papel que as atividades turísticas e didáticas podem desempenhar na conscientização pública sobre patrimônio geomorfológico possam ser ressaltadas.

\section{2. Área de estudo}

O Parque Nacional da Serra dos Órgãos (PARNASO) localiza-se no estado do Rio de Janeiro e possui uma área de 20.024 hectares, tendo sido criado em 1939 (sendo, 
portanto, o terceiro parque mais antigo do Brasil - Itatiaia, criado em 1937, e Iguaçu, também em 1939, o antecederam). O território do PARNASO está inserido na Serra do Mar e na região pertencente ao Rift Continental do Sudeste do Brasil (Riccomini, 1989; Serra e Serra, 2012), apresentando um relevo extremamente acidentado, que varia de $200 \mathrm{~m}$ a $2.275 \mathrm{~m}$ de altitude (Figura 3 ), e expressiva diversidade de fauna e flora.

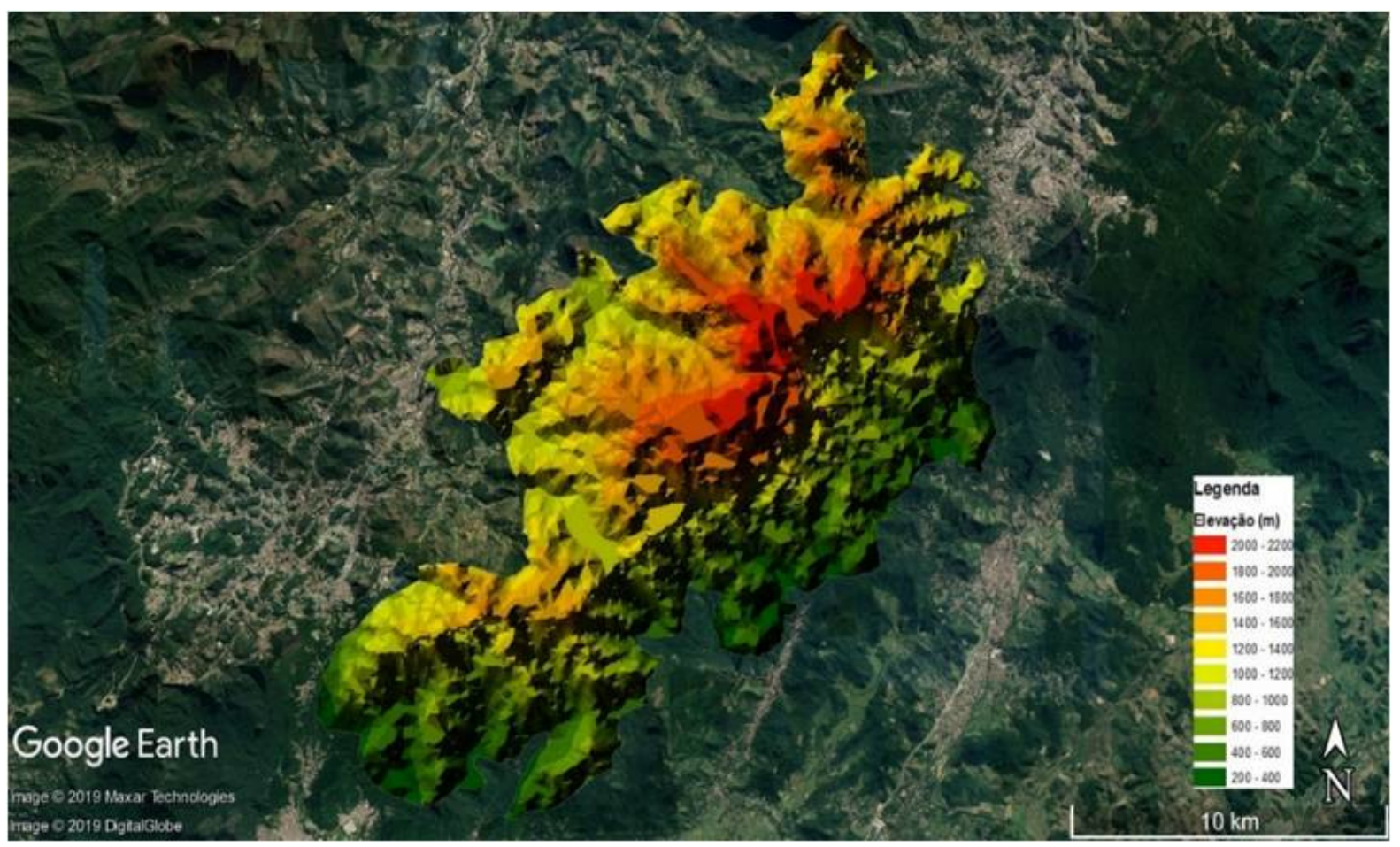

Figura 3: Modelo Digital de Elevação do PARNASO.

Dentre seus atrativos, um dos que mais se destaca em termos de uso público é a Travessia Petrópolis-Teresópolis (Figura 4), a qual possui expressivo potencial de divulgação científica a partir de propostas de interpretação ambiental que levem em consideração sua geodiversidade, além de representar a diversidade natural existente no PARNASO. Essa trilha possui aproximadamente $25 \mathrm{~km}$ de extensão, com significativa variação de altitude (cerca de 900 metros - portarias das sedes Petrópolis e Teresópolis do PARNASO - até 2.275 metros de altitude na Pedra do Sino, ponto culminante da Serra dos Órgãos), realizada, tradicionalmente, em três dias de caminhada, com os pernoites realizados nos abrigos de montanha dos Castelos do Açu e da Pedra do Sino, com opções de beliche, bivaque ou camping. A distância e a altimetria acumulada, aliadas às condicionantes naturais em que os caminhantes/montanhistas são expostos, explica o fato dela ser classificada como nível moderado/difícil de dificuldade, e de ser sugerida a contratação de um guia/condutor. 


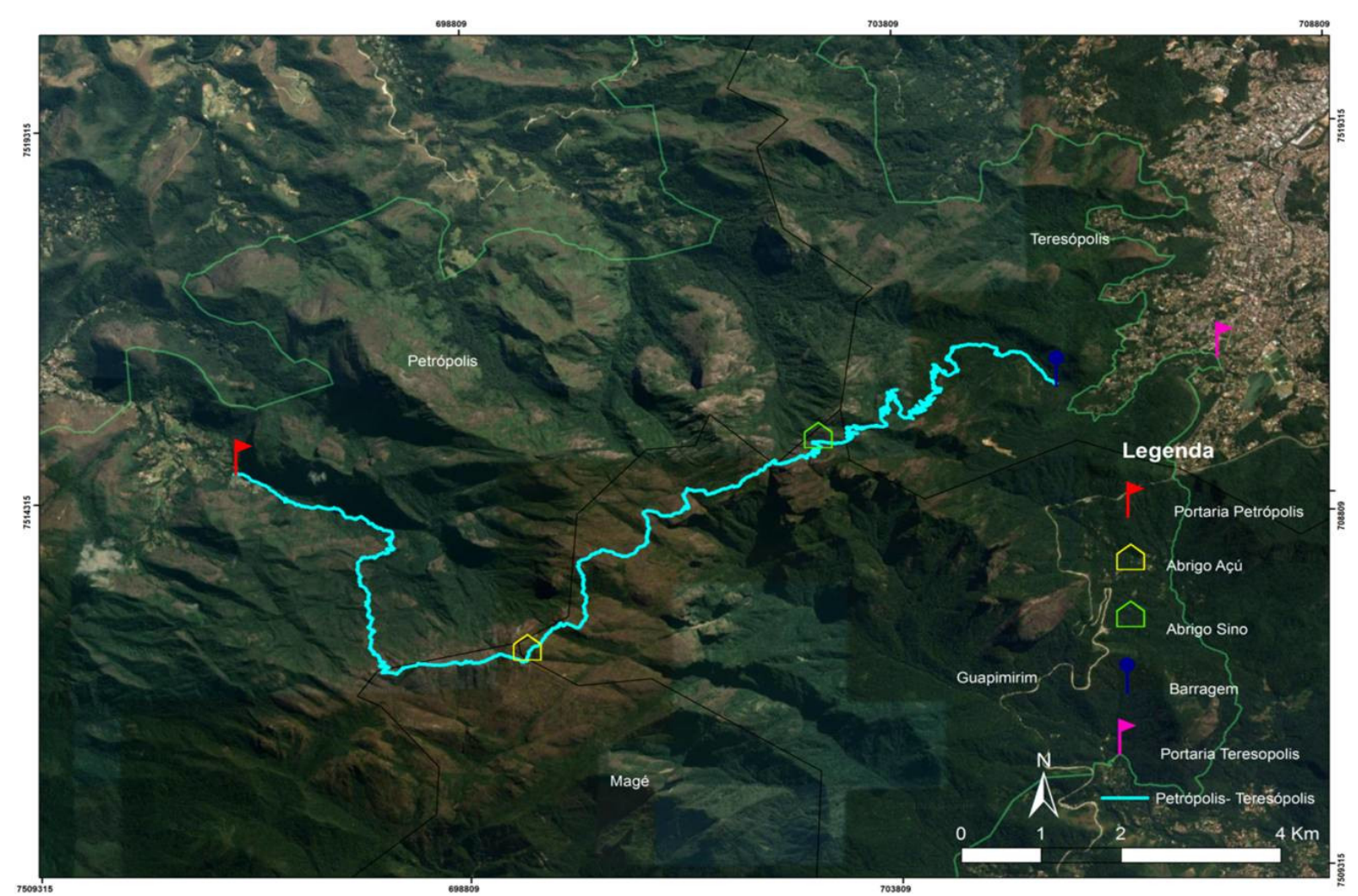

Figura 4: Travessia Petrópolis-Teresópolis (Fonte dos dados: Google Earth e Wikiloc ${ }^{\circledR}$ ).

\section{Materiais e métodos}

Para a caracterização da geodiversidade da Travessia Petrópolis-Teresópolis foi realizada, paralelamente a levantamentos de campo, uma pesquisa bibliográfica com o intuito de encontrar artigos que tivessem enfoque nos diferentes aspectos da geodiversidade do PARNASO e, se possível, que fizessem uma interligação entre eles. Também foi feita uma busca em diferentes bases, como as da Companhia de Pesquisa de Recursos Minerais (CPRM), Instituto Brasileiro de Geografia e Estatística (IBGE) e Instituto Estadual do Ambiente (INEA), para a criação de mapas que ajudassem na espacialização e elucidação da caracterização da geodiversidade na travessia. Os mapas foram confeccionados a partir do Google Earth e do ArcGis.

A elaboração do roteiro geoturístico e didático foi feito com o auxílio do aplicativo de navegação Wikiloc $^{\circledR}$, com a inclusão dos pontos de interesse da geodiversidade levantados - com fotos e descrições - e compartilhado com o nome: "GEOROTEIRO Travessia Petrópolis-Teresópolis", podendo ser acessado a partir do aplicativo pelo público em geral. $O$ aplicativo permite ainda a visualização em planta e em perfil da trilha, assim como baixar todas as informações no Google Earth, além de ser facilmente compartilhado a partir de links ou $Q R$ code e já ser amplamente utilizado por montanhistas.

A qualificação e avaliação quantitativa dos geossítios selecionados foram realizadas com base no Sistema de Cadastro e Quantificação de Geossítios e Sítios da Geodiversidade - aplicativo GEOSSIT, da CPRM - Serviço Geológico do Brasil. Tratase de um sistema de livre consulta, estruturado originalmente segundo as 
metodologias de Brilha (2005) e Garcia-Cortés e Urquí (2009) e, posteriormente, adaptado para a metodologia e conceitos de Brilha (2016). Apesar das críticas que podem ser feitas a essa metodologia, principalmente relacionadas à falta de precisão no processo de quantificação e inadequações para a perspectiva do patrimônio geomorfológico em trilhas, a mesma é interessante por priorizar a padronização dos estudos a nível nacional e permitir a comparação com outros estudos que utilizem a mesma metodologia.

\section{Resultados}

4.1 Caracterização da geodiversidade e serviços ecossistêmicos da Travessia Petrópolis-Teresópolis

O contexto geológico e tectônico regional em que a Serra dos Órgãos está inserida compreende o setor central da Província ou Sistema Orogênico Mantiqueira, o qual inclui a unidade tectônica Faixa Ribeira, onde o PARNASO inclui-se em seu Terreno Oriental (Hartwig, 2006). Essa geologia é representada na Travessia PetrópolisTeresópolis por ortognaisses e migmatitos do Complexo Rio Negro, granitóides intrusivos do Batólito da Serra dos Órgãos e maciços graníticos pós-tectônicos Granito Andorinha (Figura 5).

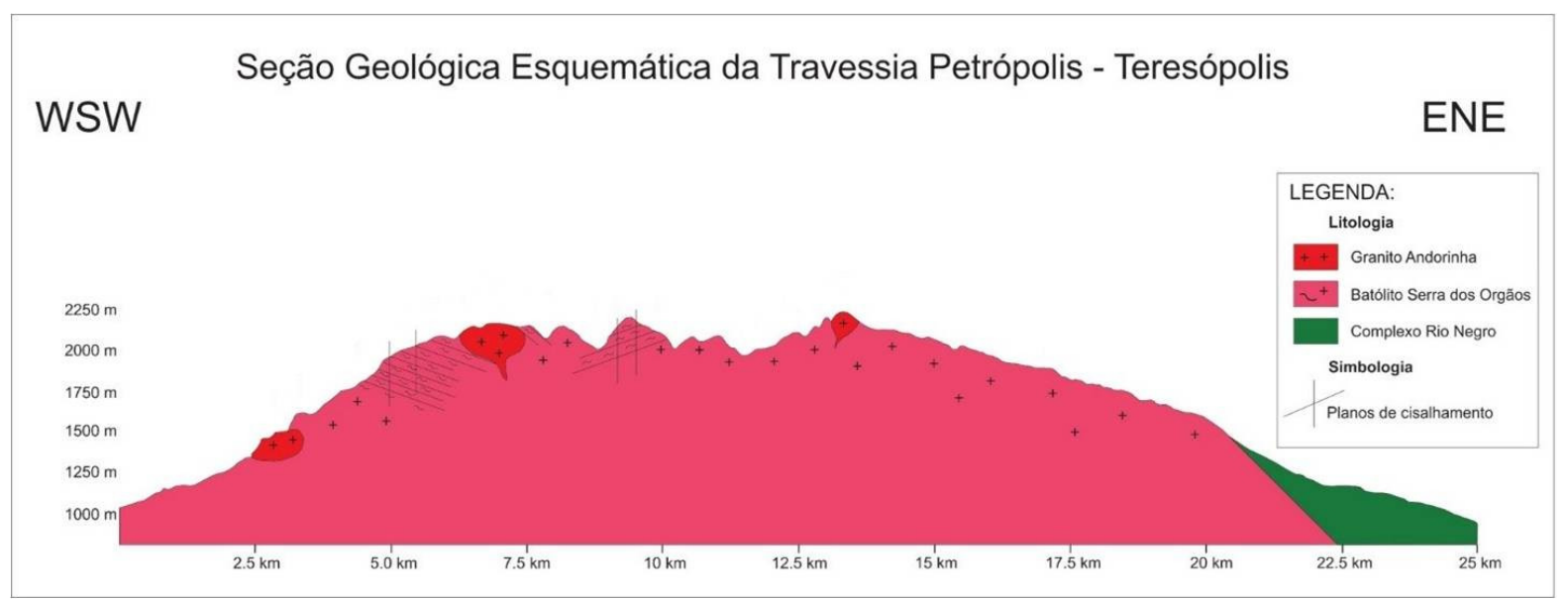

Figura 5: Seção Geológica da Travessia Petrópolis-Teresópolis (Pessoa et al., 2018).

A partir das contribuições de Oliveira et al. (2007), ao identificar as unidades de paisagem e sua implicação para o ecoturismo no PARNASO, é possível abordar a geomorfologia da travessia em duas unidades principais: as escarpas serranas, observadas da travessia pelos vales da escarpa de falha e pela escarpa de falha; e o planalto serrano, representado na travessia pelo vale do Bonfim, planalto do Açu, planalto da Pedra do Sino e planaltos dissecados (Figura 6). 


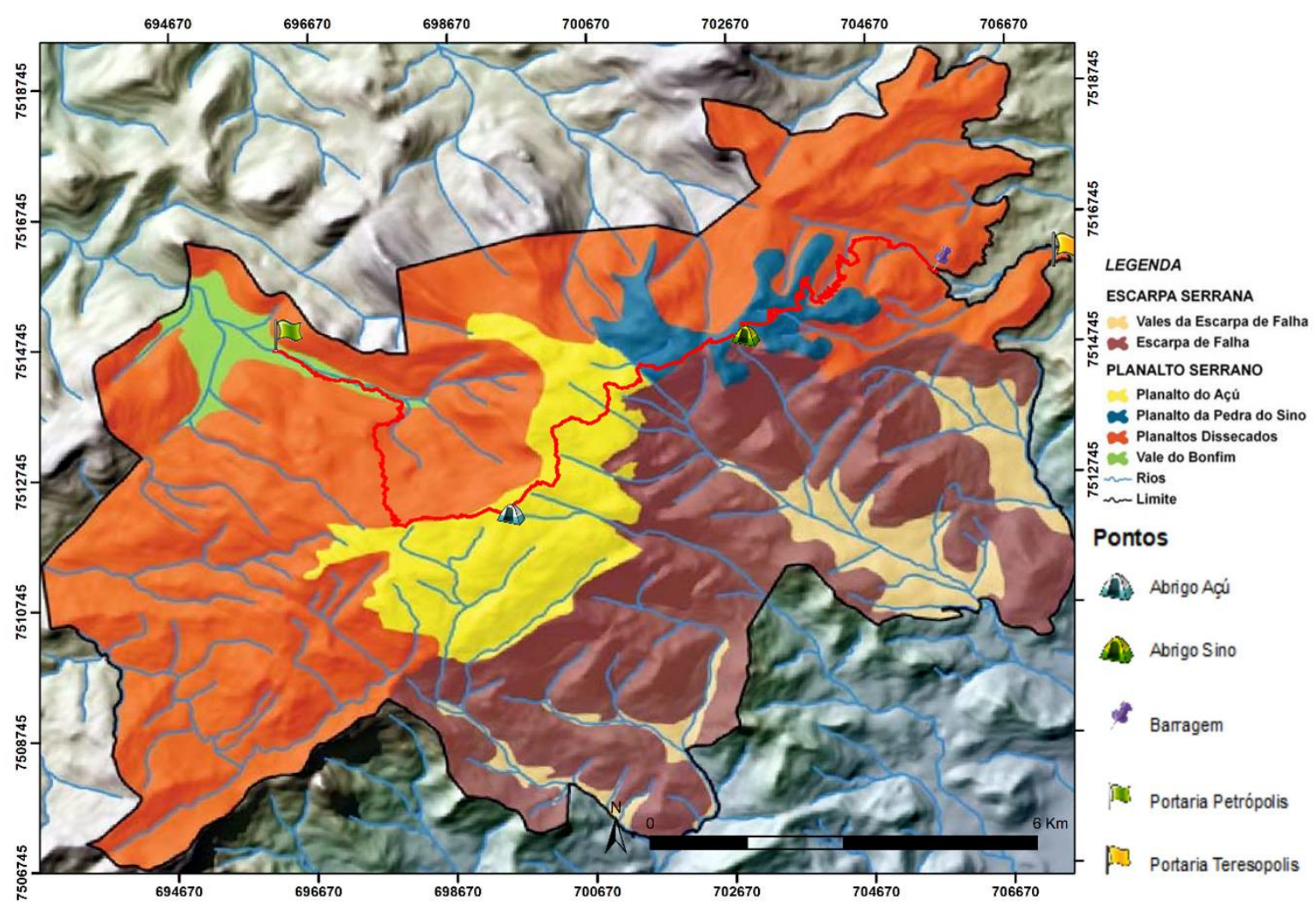

Figura 6: Domínios geomorfológicos do PARNASO no contexto da Travessia Petrópolis-Teresópolis (adaptado de Oliveira et al., 2007).

Quanto à sua hidrografia, a travessia situa-se no contexto de três bacias hidrográficas: Piabanha, Guapimirim-Macacu e Roncador (INEA, 2013). Neste aspecto é possível dar destaque à localização do abrigo de montanha dos Castelos do Açu, praticamente no divisor entre as três bacias, podendo ser alvo de discussões a respeito da hidrografia regional.

Com base em uma abordagem geossistêmica da geodiversidade da travessia, cabe ressaltar a importância da atividade hídrica como elo de integração para melhor entendimento da dinâmica da paisagem. Assim, sua dinâmica é representada por altos índices pluviométricos que, associados ao alto gradiente topográfico, produz uma alta taxa de transposição de materiais e movimentos de massa. Além disso, as zonas de falhas e fraturas tornam-se calhas naturais que, junto com o processo de erosão diferencial provocado pela maior resistência das rochas graníticas, facilitam a explicação sobre a modelagem do relevo presente na região.

Quanto aos solos, Martins et al. (2007) destacam que os fatores geológicos e geomorfológicos estão intimamente associados à organização pedológica na paisagem, apresentando em seu estudo as classes de solo observadas no PARNASO e a sua relação com os fatores geoambientais. Assim, observa-se a presença de argissolos e cambissolos no vale do Bonfim, e neossolo litólico e cambissolo ao longo das unidades planalto do Açu, planato do Sino e planaltos dissecados (Oliveira et al., 2007). Além disso, os solos, cuja formação também está intimamente relacionada com 
a alteração das rochas e com a presença de matéria orgânica, a partir do processo de ciclagem de nutrientes, estabelecem a conexão entre a geo e a biodiversidade.

Nessa perspectiva de interpretação ambiental, um destaque pode ser dado para o aspecto integrador dos solos, sendo possível ressaltar a importância das rochas em sua formação, sua importância na formação do relevo e das diferentes paisagens, seu papel na sustentabilidade dos ecossistemas, além das possibilidades de serem aproveitados como instrumento pedagógico por meio da geoeducação (Guerra, 2018).

Já a cobertura vegetal presente na travessia expressa a relação com os aspectos da geodiversidade ao apresentar diferenciações conforme a posição no relevo. Quanto à sua fitofisionomia, situa-se no bioma Mata Atlântica e, por conta da expressiva variação altitudinal, é possível observar uma variação de ecossistemas (Rizzini, 1979), sendo eles: floresta pluvial montana, floresta pluvial alto-montana e campos de altitude (IBGE, 2012).

Esta caracterização permite destacar que detalhar, registrar e divulgar aspectos da geodiversidade em trilhas contribui no destaque da dimensão estética da paisagem, da sua dimensão dinâmica, ao identificar e visualizar processos e mudanças, e também da sua imbricação de escalas, seja espacial ou temporal, o que está relacionado aos serviços ecossistêmicos de conhecimento, culturais, provisão, regulação e suporte, apresentados por Gray (2013) e todos presentes na Travessia Petrópolis-Teresópolis e, logo, no PARNASO.

\subsection{Roteirização geoturística e didática com o uso do aplicativo Wikiloc ${ }^{\circledR}$}

Para a roteirização geoturística e didática, os pontos de interesse da geodiversidade (Tabela I) foram levantados em trabalhos de campo a partir da caracterização prévia apresentada anteriormente. Esses pontos de interesse abordam aspectos da geodiversidade integrados também com aspectos históricos e culturais, melhor descritos a seguir.

No primeiro dia da Travessia, observa-se a existência de diferentes ecossistemas da Mata Atlântica, condicionados por inúmeras variáveis - como o desnível altimétrico e a espessura do solo, estabelecendo uma importante interface entre o substrato rochoso e a vegetação. Na parte inicial da trilha, que compreende o compartimento de relevo do Vale do Bonfim com a presença de Floresta Montana, há a presença de blocos de rocha em seu leito encaixado que acompanha o relevo, onde apura-se a percepção de diversos sentidos, como o olfato e a audição. Próximo ao ponto de interesse da Pedra do Queijo, os afloramentos rochosos começam a ficar mais presentes e o panorama observado na trilha começa a ficar maior, privilegiando abordagens na escala da paisagem em um Planalto Dissecado com porte arbóreo baixo do ecossistema Alto-Montana. Ao alcançarmos a cota dos $2.000 \mathrm{~m}$ de altitude, no ponto conhecido como "Chapadão", destaca-se o compartimento de relevo do Planalto do Açu, com mudança na vegetação - a partir daí os campos de altitude tornam-se predominantes. É possível ainda observar o divisor entre as bacias hidrográficas do Piabanha (ao norte) e Baía de Guanabara (ao sul), levantando um 
importante aspecto da hidrografia do Estado do Rio de Janeiro. Os Castelos do Açu, representados por blocos do Granito Andorinha que chegam a 10 metros de altura, originados a partir da combinação entre atuação intempérica, litologia e descompressão adiabática, marcam o fim da trilha do primeiro dia da Travessia Petrópolis-Teresópolis.

Tabela I: Pontos de Interesse da Geodiversidade

\begin{tabular}{|c|c|c|}
\hline \multicolumn{3}{|c|}{$\begin{array}{l}\text { PONTOS DE INTERESSE DA GEODIVERSIDADE } \\
\text { TRAVESSIA PETRÓPOLIS-TERESÓPOLIS (PARNASO) }\end{array}$} \\
\hline $1^{\circ} \mathrm{DIA}$ & $2^{\circ} \mathrm{DIA}$ & $3^{\circ}$ DIA \\
\hline 1: Portaria / sede Petrópolis & 1: Abrigo Açu & 1: Abrigo 4 \\
\hline $\begin{array}{c}\text { 2: Bifurcação para o Poço da } \\
\text { Ducha }\end{array}$ & 2: Morro do Marco & 2: Pedra da Baleia \\
\hline $\begin{array}{l}\text { 3: Bifurcação para a } \\
\text { Cachoeira Véu da Noiva }\end{array}$ & 3: Vale da Luva & 3: Cota 2000 \\
\hline 4: Mirante & 4: Morro da Luva & 4: Abrigo 3 \\
\hline 5: Pedra do Queijo & $\begin{array}{l}\text { 5: Xenólito na descida para a } \\
\text { Cachoeirinha }\end{array}$ & 5: Mirante do Abrigo 3 \\
\hline 6: Afloramento antes do Ajax & 6: Cachoeirinha & 6: Cicatriz de Deslizamento \\
\hline 7: Pedra do Ajax & 7: Trecho Técnico: Elevador & 7: Abrigo 2 \\
\hline 8: Intemperismo Isabeloca & 8: Pico do Elevador & 8: Cachoeira Véu da Noiva \\
\hline 9: Chapadão & 9: Morro do Dinossauro & 9: Abrigo 1 \\
\hline 10: Mirante Graças a Deus & 10: Vale das Antas & 10: Calçamento Histórico \\
\hline 11: Mirante do Cruzeiro & 11: Pedra da Baleia & $\begin{array}{l}\text { 11: Barragem / sede } \\
\text { Teresópolis }\end{array}$ \\
\hline 12: Castelos do Açu & 12: Terra de Gigantes & - \\
\hline 13: Abrigo Açu & 13: Trecho Técnico: Mergulho & - \\
\hline- & $\begin{array}{l}\text { 14: Trecho Técnico: } \\
\text { Cavalinho }\end{array}$ & - \\
\hline- & 15: Pedra do Sino & - \\
\hline- & 16: Blocos Granito Andorinha & - \\
\hline- & 17: Abrigo 4 & - \\
\hline
\end{tabular}

No segundo dia, a caminhada alterna subidas e descidas íngremes entre os compartimentos de relevo Planalto do Açu e Planalto do Sino, com a presença de ecossistemas de campos de altitude e floresta Alto-Montana. No ponto de interesse do Morro do Marco, questões sobre o panorama geotectônico regional destacam-se. As rochas presentes na Travessia foram originadas em um ambiente de colisão de placas tectônicas que resultaram na formação do Paleocontinente Gondwana. Assim, caminhamos sobre gnaisses do Complexo Rio Negro ( 630 milhões de anos), gnaisses graníticos do Batólito da Serra dos Órgãos ( 560 milhões de anos) e maciços graníticos pós-colisionais - Granito Andorinha ( 480 milhões de anos). Enquanto os 
afloramentos do Batólito são predominantes, o Granito Andorinha encontra-se nas partes mais elevadas (Castelos do Açu e Pedra do Sino, por exemplo), e o Complexo Rio Negro pode ser observado na forma de xenólitos, representados por "corpos estranhos" ou "enclaves" presentes no Batólito da Serra dos Órgãos. Mais adiante, no ponto de interesse do Morro da Luva, são as discussões sobre o relevo da Serra dos Órgãos que podem ser abordados. Formado a partir do soerguimento das rochas existentes, que configuram a paisagem atual, este resulta de uma combinação de intemperismo diferencial entre gnaisses e granitos, caracterizando distintas resistências aos processos intempéricos e erosivos. Na Pedra do Sino, ponto culminante da Serra dos Órgãos, com $2.275 \mathrm{~m}$ de altitude, sobre o compartimento geomorfológico do Planalto do Sino onde aflora o Granito Andorinha, também é possível observar as bacias hidrográficas da Baía de Guanabara e do Piabanha, e todo um conjunto de montanhas do Estado do Rio de Janeiro. Em direção à Baía de Guanabara, fica evidente ainda a escarpa serrana, representada pela escarpa de falha e pelos vales da escarpa de falha, áreas com expressivo desnível altimétrico, com forte incisão nos vales ao longo de falhas e fraturas subverticais, exemplificado por diversas paisagens observadas ao longo da Travessia.

Já o terceiro dia começa no Planalto do Sino, coberto pelos campos de altitude. Após cerca de $1.5 \mathrm{~km}$ de caminhada, um bloco de rocha marca a cota de 2.000 metros de altitude e a partir desse ponto a caminhada passa a percorrer um desnível altimétrico significativo, reflexo de mudanças no compartimento de relevo, onde ocorre mudança do Planalto do Sino para o Planalto Dissecado. Mudanças também são percebidas na vegetação, onde os campos de altitude são substituídos por um ambiente florestal na encosta. No mirante do Abrigo 3 é possível observar o contexto serrano regional, com destaque para a cidade de Teresópolis, possibilitando a realização de discussões a respeito da sua evolução urbana. $O$ trecho final da Travessia é marcado pela presença de um calçamento histórico construído ainda no período imperial, antes mesmo da criação do PARNASO.

Todos os pontos foram inseridos no aplicativo de navegação Wikiloc ${ }^{\circledR}$, junto com fotos e descrições de cada um. O usuário do aplicativo pode acompanhar esses pontos de interesse da geodiversidade distribuídos ao longo da trilha com uma visão tanto em planta como em perfil do terreno (Figura 7). 

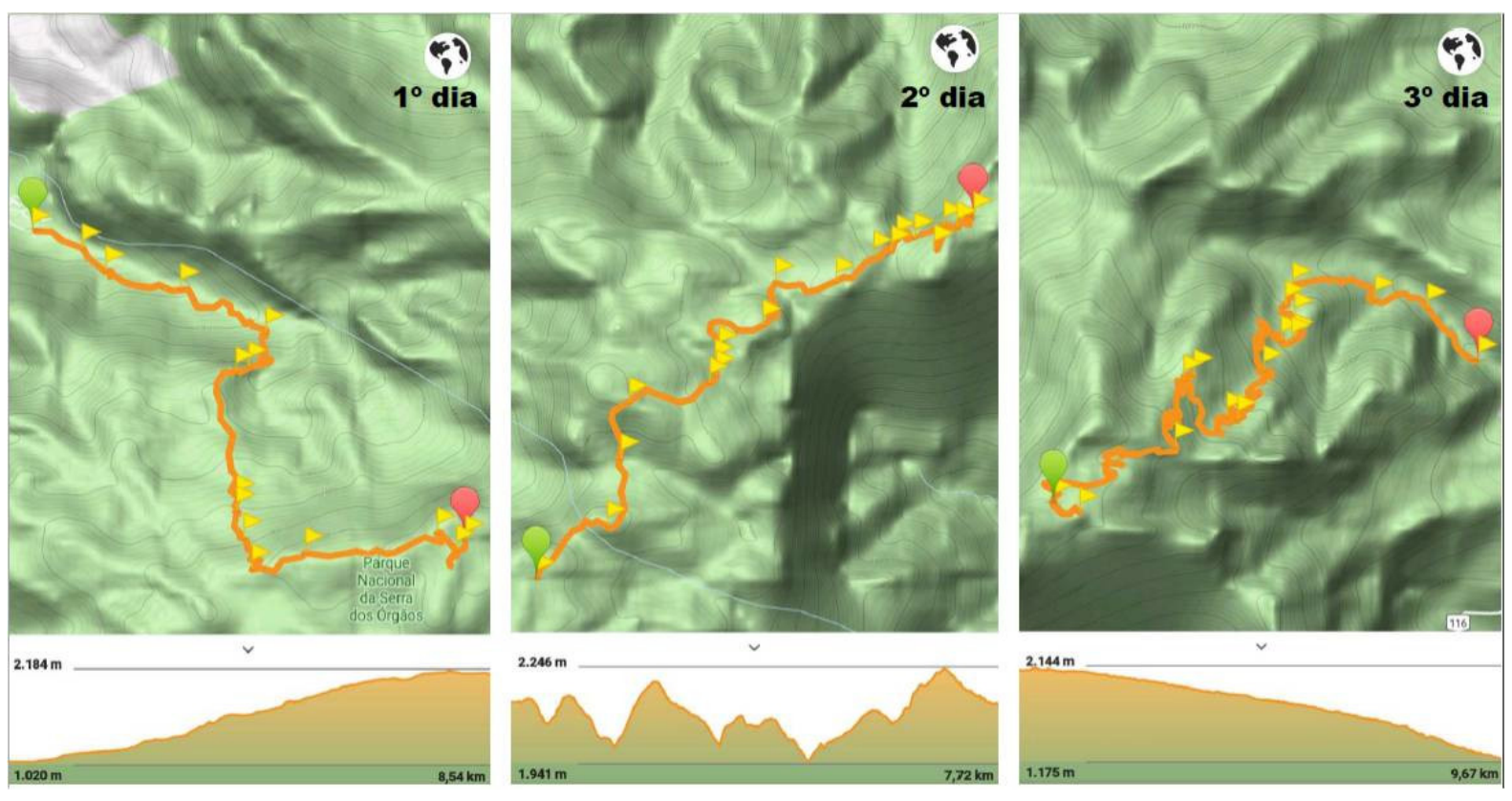

Figura 7: Distribuição dos pontos de interesse da geodiversidade ao longo da trilha, conforme visualizado no celular dos usuários a partir do aplicativo Wikiloc ${ }^{\circledR}$.

O roteiro elaborado também pode ser acessado pelo site do $W i k i l o c^{\circledR}$, onde é possível baixar a trilha e todas as informações associadas em diferentes plataformas, dentre elas o Google Earth, o que torna possível a realização de diferentes tipos de trabalhos com as informações geradas, além de diferentes formas de representação, ilustração e espacialização dessas informações, conforme ilustrado na Figura 8.

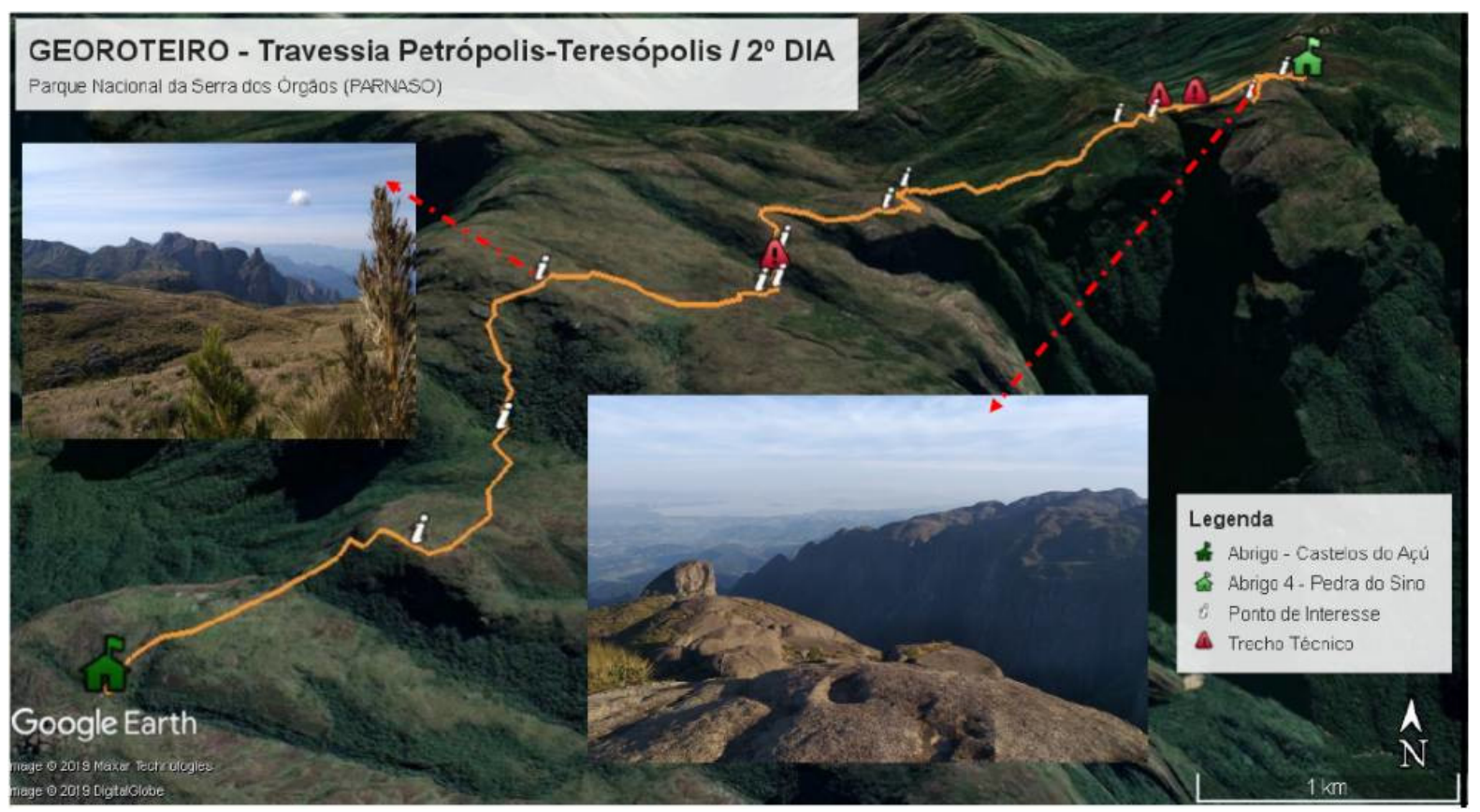

Figura 8: Possibilidades de representação das informações do roteiro geoturístico e didático com o uso do Google Earth. 
Além disso, destacam-se as possibilidades de divulgação do roteiro (Figura 9) a partir do QR CODE ou link de acesso, os quais podem ser compartilhados por diferentes meios, como e-mail e redes sociais, por exemplo.
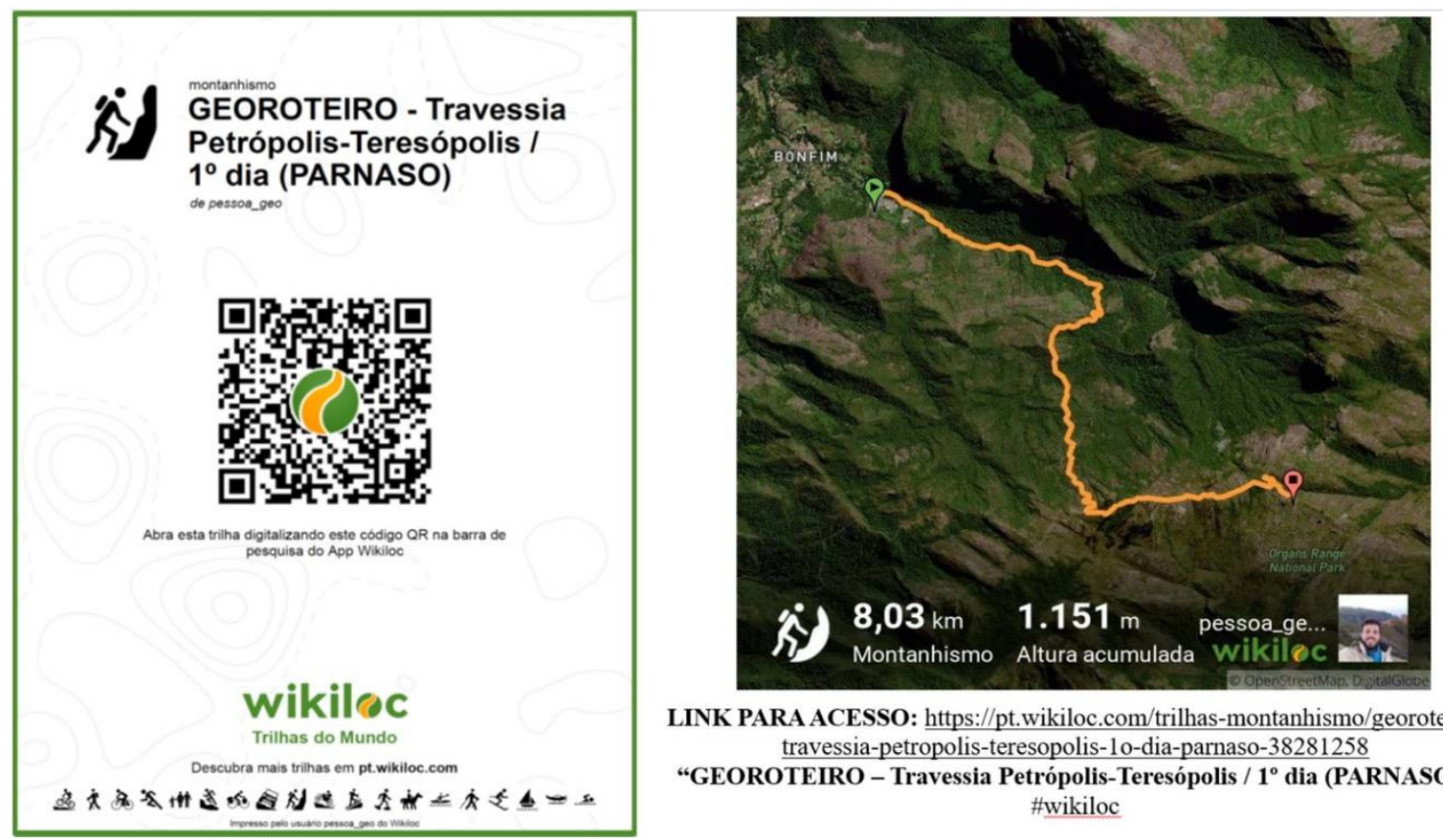

LINK PARA ACESSO: https://pt.wikiloc.com/trilhas-montanhismo/georoteirotravessia-petropolis-teresopolis-1o-dia-parnaso-38281258

“GEOROTEIRO - Travessia Petrópolis-Teresópolis / $1^{\circ}$ dia (PARNASO)” \#wikiloc

Figura 9: Possibilidades de divulgação do roteiro - QR CODE ou link para acesso.

https://pt.wikiloc.com/trilhas-montanhismo/georoteiro-travessia-petropolis-teresopolis-10-dia-parnaso$\underline{38281258}$

\subsection{Cadastro no GEOSSIT}

Como forma de contribuir no inventário nacional de geossítios, foram cadastrados quatro geossítios no Sistema de Cadastro e Quantificação de Geossítios e Sítios da Geodiversidade (GEOSSIT), concebido pela Companhia de Pesquisa de Recursos Minerais do Brasil (CPRM), conforme apresentado na Tabela II.

Tabela II: Geossítios cadastrados no aplicativo GEOSSIT da CPRM, com seus respectivos interesses, interesses associados e possibilidades de uso.

\begin{tabular}{|c|c|c|c|}
\hline $\begin{array}{c}\text { GEOSSÍTIOS } \\
\text { CADASTRADOS }\end{array}$ & INTERESSE & $\begin{array}{l}\text { INTERESSE } \\
\text { ASSOCIADO }\end{array}$ & USO \\
\hline Pedra do Sino & \multirow{4}{*}{$\begin{array}{c}\text { Geomorfológico; } \\
\text { Hidrológico; } \\
\text { Petrológico; } \\
\text { Tectono-Estrutural. }\end{array}$} & \multirow{4}{*}{$\begin{array}{l}\text { Expressão cênica; } \\
\text { Ecológico; } \\
\text { Histórico-cultural; } \\
\text { Valor Estético. }\end{array}$} & \multirow{4}{*}{$\begin{array}{l}\text { Turístico; } \\
\text { Científico; } \\
\text { Educativo. }\end{array}$} \\
\hline Castelos do Açu & & & \\
\hline Portais de Hércules & & & \\
\hline Terra de Gigantes & & & \\
\hline
\end{tabular}

Quanto à caracterização destes geossítios, todos estão inseridos dentro da Província da Mantiqueira, e com intervalo de tempo geológico entre o Neoproterozóico e 
Cambriano. A Pedra do Sino e os Castelos do Açú encontram-se incorporados à Unidade Litodêmica denominada Suíte Nova Friburgo (Granito Andorinha) - composta por granito pórfiro -, e os Portais de Hércules e Terra de Gigantes incorporados à Suíte Serra dos Órgãos, onde o gnaisse granítico é a rocha predominante. As feições de relevo podem ser enquadradas desde escarpas e escarpas estruturais a planaltos e vales encaixados, tendo picos ou cumes associados. Porém, numa perspectiva geossistêmica de análise da paisagem, e com grandes contribuições dos aspectos teóricos sobre geomorfossítios, essas rochas tornam evidentes, conjuntamente, os processos que dão origem às paisagens em que os visitantes da trilha estão inseridos.

A partir da quantificação proposta pelo aplicativo GEOSSIT, todos os geossítios cadastrados foram enquadrados como de relevância nacional, de valor científico, com valores educativo e turístico também de relevância nacional, e risco de degradação baixo (Figura 10).
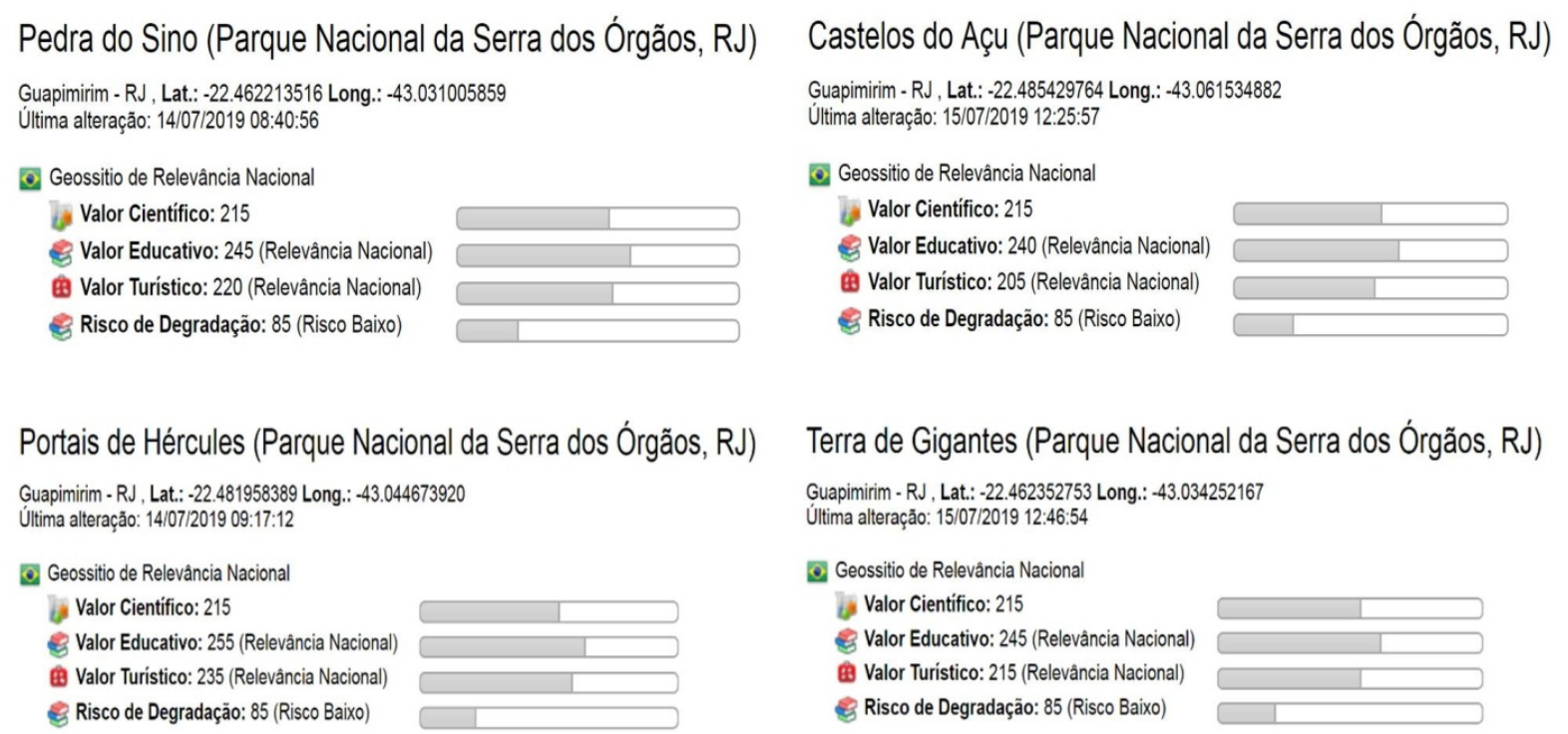

Figura 10: Geossítios cadastrados no aplicativo GEOSSIT da CPRM com suas respectivas quantificações.

\section{Conclusões}

O conhecimento da geodiversidade do PARNASO contribui para a gestão dos elementos do seu meio físico (abióticos), que poderá ser incorporado para uma visão integral da sua diversidade natural (elementos bióticos e abióticos). Além disso, os dados obtidos da geodiversidade local agregaram valores científicos e serviram como base para a elaboração de roteiros geoturísticos e didáticos, representando estratégias de divulgação científica. Deste modo, favorecem e estimulam as atividades educativas e do geoturismo local, contribuindo para a conservação deste território.

Embora a proteção dos valores científicos e educacionais do geopatrimônio continue a ser uma atividade central, a geoconservação está evoluindo para adotar uma 
abordagem mais integrada ligando a geodiversidade, a biodiversidade, a paisagem e as pessoas. Assim, a diversidade natural, a partir de uma abordagem holística, pode ser avaliada em diferentes escalas espaciais e temporais, como em trilhas inseridas ou não em áreas protegidas, e ressignificar as relações entre sociedade e natureza.

O presente trabalho ressalta a importância de se inventariar, sinalizar e divulgar a geodiversidade em trilhas através de uma abordagem interdisciplinar nas geociências. Com isso, os valores científicos, históricos, culturais e educacionais atribuídos à geodiversidade local são divulgados de modo que se crie uma identidade cultural e afetuosa para aqueles que querem usufruir de seus serviços ecossistêmicos e contribuir para sua conservação.

\section{Bibliografia}

Assis Junior, H. (2011). Litografias e obras artísticas na Flora Brasiliensis. Revista de História da Arte e Arqueologia, 15, 95-110. Disponível em: https://www.unicamp.br/chaa/rhaa/downloads/Revista\%2015\%20-\%20artigo\%205.pdf

Brilha, J. (2005). Património Geológico e Geoconservação: A Conservação da Natureza na sua Vertente Geológica. Braga: Palimage Editores.

Brilha, J. (2016). Inventory and Quantitative Assessment of Geosite and Geodiversity Sites: a Review. Geoheritage, 8(2), 119-134. https://doi.org/10.1007/s12371-014-0139-3

Brilha, J. (2018). Geoheritage: inventories and evaluation. In: Reynard, E., Brilha, J. (Eds.). Geoheritage: Assessment, Protection and Management. Amsterdam: Elsevier.

Coratza, P., Hobléa, F. (2018). The Specificities of Geomorphological Heritage. In: Reynard, E., Brilha, J. (Eds.). Geoheritage: Assessment, Protection and Management. Amsterdam: Elsevier.

Garcia-Cortés, A.; Urquí, L.C. (2009). Documento Metodológico para la elaboracion del inventario espanñol de lugares de interés geológico (IELIG). Madrid: Instituto Geológico y Minero de España.

Guerra, A. J. T. (2018). O papel dos solos sob a ótica do geoturismo, da geodiversidade e da geoconservação. In: Guerra, A. J. T.; Jorge, M. C. O. (Orgs.) Geoturismo, Geodiversidade e Geoconservação: abordagens geográficas e geológicas. São Paulo, Oficina de Textos.

Gray, M. (2013). Geodiversity: valuing and conserving abiotic nature (2th ed.). Chichester: John Wiley \& Sons.

Hartwig, M. E. (2006). Tectônica rúptil mosozóico-cenozóica na região da Serra dos Órgãos, $R J$. Dissertação de Mestrado, Instituto de Geociências, Universidade de São Paulo.

IBGE - Instituto Brasileiro de Geografia e Estatística (2012). Manual técnico da vegetação brasileira: sistema fitogeográfico, inventário das formações florestais e campestres, técnicas e manejo de coleções botânicas, procedimentos para mapeamentos. Rio de janeiro: IBGE- Diretoria de Geociências.

INEA - Instituto Estadual do Ambiente (2013). Resolução CERHI-RJ No 107. Rio de Janeiro.

Lucena, W. M. (2008). História do Montanhismo no Rio de Janeiro. Rio de Janeiro: PUBLIT. 
Martins, E. S., Carvalho Júnior, O., Souza, V., Couto Júnior, A., Oliveira, S., Gomes, R., Reatto, A. (2007). Relação solo-relevo em vertentes assimétricas no Parque Nacional da Serra dos Órgãos, RJ. Revista Brasileira de Geomorfologia, 8(1), 45-62. http://dx.doi.org/10.20502/rbg.v8i1.85

Menezes, P. C. (2017). O aprendizado brasileiro das trilhas de longo curso no mundo. (O) eco. Disponível em: http://www.oeco.org.br/colunas/pedro-da-cunha-e-menezes/oaprendizado-brasileiro-das-trilhas-de-longo-curso-no-mundo/

Newsome, D., Dowling, R. (2018). Geoheritage and Geotourism. In: Reynard, E., Brilha, J. (Eds.). Geoheritage: Assessment, Protection and Management. Amsterdam: Elsevier.

Oliveira, S. N., Carvalho Junior, O. A., Martins, E. S., Silva, T. M., Gomes, R. A. T., Guimarães, R. F. (2007). Identificação de Unidade de Paisagem e sua implicação para o ecoturismo no Parque Nacional da Serra dos Órgãos. Revista Brasileira de Geomorfologia, 8(1), 87107. http://dx.doi.org/10.20502/rbg.v8i1.88

Panizza, M. (2001). Geomorphosites: Concepts, methods and examples of geomorphological survey. Chinese Science Bulletin, 46(1), 4-5. https://doi.org/10.1007/BF03187227

Pessoa, F., Araujo, J., Seoane, J. C., Cambra, M. F., Giraldo, S., Martins, G., Mansur, K., Peixoto, M. N. (2018). Geodiversidade e serviços ecossistêmicos em trilhas de montanha na Travessia Petrópolis-Teresópolis (Parque Nacional da Serra dos Órgãos, RJ). In: XII Simpósio Nacional de Geomorfologia, Crato - Ceará.

Reynard, E. (2009). Geomorphosites: definition and characteristics. In: Reynard, E., Coratza, P., Regolini- Bissig, G. (Eds.), Geomorphosites (pp. 9-20). Munchen: Pfeil Verlag.

Reynard, E., Giusti, C. (2018). The Landscape and the Cultural Value of Geoheritage. In: Reynard, E., Brilha, J. (Eds.). Geoheritage: Assessment, Protection and Management. Amsterdam: Elsevier.

Riccomini, C. O. (1989). Rift continental do sudeste do Brasil. Tese de Doutorado, Instituto de Geociências, Universidade de São Paulo.

Rizzini, C. T. (1997). Tratado de Fitogeografia do Brasil: aspectos ecológicos, sociológicos e florísticos. Rio de Janeiro: Âmbito Cultural Edições Ltda.

Rodriguez, J. M. M., Silva, E. V. (2019). Teoria dos Geossistemas - olegado de V.B. Sochava: Volume I. Fundamentos Teórico-Metodológicos. Fortaleza: Edições UFC.

Serra, M. V., Serra, M. T. F. (2012). Guia de História Natural do Rio de Janeiro. Rio de Janeiro: Cidade Viva.

Sochava, V. B. (1978). Por uma teoria de classificação de geossistemas de vida terrestre. Biogeografia. São Paulo: IG-USP.

Artigo recebido em/ Received on: 12/11/2019

Artigo aceite para publicação em/ Accepted for publication on: 29/12/2019 